www.nature.com/pj

\title{
Preparation and characterization of organosoluble polyimide/BaTiO 3 composite films with mechanical- and chemical-treated ceramic fillers
}

\author{
Chia-Yang Lin ${ }^{1}$, Dong-Hau Kuo ${ }^{1}$, Fong-Ren Sie ${ }^{1}$, Ju-Yin Cheng ${ }^{1}$ and Guey-Sheng Liou ${ }^{2}$ \\ Organosoluble polyimide $(\mathrm{PI}) /$ barium titanate $\left(\mathrm{BaTiO}_{3}\right)$ hybrid composites using different types of treated ceramic powders were \\ prepared and investigated for their dielectric performance. The soluble coPI poly( $p$-hydroxy-imide) (PI-2) constituted by $4,4^{\prime}$ - \\ oxydiphthalic dianhydride/2,2-bis(3-amino-4-hydroxyphenyl)hexafluoropropane/4,4'-oxydianiline exhibited a higher dielectric \\ constant $(K)$ of 7.4. The ceramic fillers used in the study were multi-doped self-synthesized $\mathrm{BaTiO}_{3}$ (SS-BT) and commercially \\ available $\mathrm{BaTiO}_{3}$ powders. Up to $50 \mathrm{vol} \%$ ceramic fillers were added to the $\mathrm{PI}$, and the resulting dielectric properties were \\ studied. The $\mathrm{BaTiO}_{3}$ fillers underwent particle-size refinement using planetary ball milling and surface modifications through the \\ oxidation of hydrogen peroxide and by grafting with a coupling agent of 3 -glycidoxypropyltrimethoxysilane. The highest $K$-value \\ obtained from the PI-2/SS-BT composites was 52 at a 50 vol\% filler content. However, the high- $K$ advantage of SS-BT for \\ hybrid composites is greatly deteriorated by surface modification of the $\mathrm{OH}^{-}$group covering the fillers.
}

Polymer Journal (2012) 44, 1131-1137; doi:10.1038/pj.2012.79; published online 16 May 2012

Keywords: composites; dielectric properties; hybrid composite; polyimides

\section{INTRODUCTION}

Flexible electronics, which are lightweight, easily bent and folded and are mountable on uneven surfaces, have attracted much attention for applications in displays, solar cells, semiconductors, lighting and remote sensing. ${ }^{1,2}$ In addition to the fabrication of flexible transistors, diodes and conductors, flexible passive components such as capacitors and substrate materials are also important.

In designing flexible substrates, the sustainable processing temperature, match in coefficient of thermal expansion with devices, chemical resistance, gas permeability and surface smoothness must be considered. Polyimide (PI), which has a high glass transition temperature $\left(\mathrm{T}_{\mathrm{g}} \sim 360^{\circ} \mathrm{C}\right)$, excellent tensile strength, chemical inertness and a low coefficient of thermal expansion (3.4 p.p.m. $\mathrm{K}^{-1}$ ), has been widely used in microelectronic industries. ${ }^{3}$ Because PIs are generally insoluble in organic solvents, they are usually prepared using a two-step method, that is, the formation of a soluble polyamic acid (PAA) precursor between diamine and dianhydride monomers followed by thermal imidization at $300^{\circ} \mathrm{C}$. However, this method has drawbacks such as the instability of PAA solution and the liberation of water during imidization. Compared with the two-step method, the one-step method synthesizes PIs by mixing monomers in solution to form a PI precursor at room temperature, followed by direct imidization in solvent at $180-190^{\circ} \mathrm{C}$. For this method, the reaction temperature is lower, water can be removed during imidization and the solvent is the only component that needs to be removed from the PI solution to form the PI film. ${ }^{4}$ Functionalization of PIs for the enhancement of optical, thermal and electrical properties can be achieved by incorporating second phases to form hybrid composites. Early fabrication of hybrid composites aimed at mechanical and optical properties focused on the incorporation of $\mathrm{SiO}_{2},{ }^{5-8} \mathrm{TiO}_{2},{ }^{9,10}$ and $\mathrm{Al}_{2} \mathrm{O}_{3}{ }^{11}$ alkoxides into a PAA solution before casting and thermal imidization.

To enhance dielectric properties, organic/inorganic barium titanate $\left(\mathrm{BaTiO}_{3}\right)$ hybrid composites are of interest because of the ferroelectric behavior of $\mathrm{BaTiO}_{3}$ with a high dielectric constant $(K)$ of $\sim 6000$ at a fine grain size of $\sim 1 \mathrm{~mm} .{ }^{12}$ Chon et al..$^{13}$ demonstrated a ultravioletcured hybrid composite with $\mathrm{K}_{10 \mathrm{kHz}}=55$ using $14 \mathrm{vol} \%$ phosphatemodified $\mathrm{BaTiO}_{3}$ in a hybrid matrix containing fluorine-filled diphenol, siloxane and methacrylate groups. The siloxane and halogenated bisphenol A moieties with high electronic polarizability yielded the highest $K$-value. 3-glycidoxypropyltrimethoxysilane (GPTMS)-modified and untreated $\mathrm{BaTiO}_{3}$ /epoxy composites had

\footnotetext{
${ }^{1}$ Department of Materials Science and Engineering, National Taiwan University of Science and Technology, Taipei, Taiwan and ${ }^{2}$ Institute of Polymer Science and Engineering, National Taiwan University, Taipei, Taiwan

Correspondence: Professor D-H Kuo, Department of Materials Science and Engineering, National Taiwan University of Science and Technology, N0. 43, Sector 4, Keelung Road, Taipei 10607, Taiwan.

E-mail: dhkuo@mail.ntust.edu.tw

or Professor G-S Liou, Institute of Polymer Science and Engineering, National Taiwan University, Taipei 10607, Taiwan.

E-mail: gsliou@ntu.edu.tw
}

Received 21 December 2011; revised 23 March 2012; accepted 26 March 2012; published online 16 May 2012 
$\mathrm{K}_{10 \mathrm{kHz}}$ values of 50 and 38, respectively, at $60 \mathrm{vol} \% \mathrm{BaTiO}_{3} \cdot{ }^{14,15}$ Multi-doped $\mathrm{BaTiO}_{3} /$ epoxy composites yielded $\mathrm{K}_{100 \mathrm{kHz}}=44$ at 40 vol\% ceramic content. ${ }^{16,17}$ Polyvinylidene fluoride-based ferroelectric copolymers have been used as rigid matrices to enhance the dielectricity of hybrid composites. ${ }^{18,19}$ Limited reports are available on $\mathrm{PI} / \mathrm{BaTiO}_{3}$ composites. $^{20-22}$ For silane-modified or untreated $\mathrm{BaTiO}_{3}$, the $\mathrm{K}_{10 \mathrm{kHz}}$ values were $18-28$ at $40 \mathrm{vol} \% \mathrm{BaTiO}_{3}$ or reached 35 at 50 vol\%. The aforementioned $\mathrm{PI} / \mathrm{BaTiO}_{3}$ composites were formed by incorporating fillers into a PAA solution, spin coating the solution onto substrates and then heating to imidization at $300^{\circ} \mathrm{C}$. In general, the two-step process was used to prepare the $\mathrm{PI} / \mathrm{BaTiO}_{3}$ composites.

In this study, our $\mathrm{PI} / \mathrm{BaTiO}_{3}$ hybrid composites were prepared by mixing the organosoluble PI derived from the one-step polymerization with $\mathrm{BaTiO}_{3}$ in dimethylacetamide, screen printing the pastes to form composite films and drying at $90{ }^{\circ} \mathrm{C}$ for $24 \mathrm{~h}$. The lowtemperature process is a key for the PI-based flexible devices to be integrated with flexible electronics. Imidization of PAA at $300{ }^{\circ} \mathrm{C}$ for flexible capacitors will damage other functional polymers. Selfsynthesized (SS) and commercially available $\mathrm{BaTiO}_{3}$ powders added into the PI matrices were planetary ball milled, oxidized by hydrogen peroxide $\left(\mathrm{H}_{2} \mathrm{O}_{2}\right)$ to form hydroxyl groups or modified with the silane coupling agent of GPTMS. The effects of different contents and treatments of $\mathrm{BaTiO}_{3}$ on the composition homogeneity and dielectric performance of $\mathrm{PI} / \mathrm{BaTiO}_{3}$ hybrid composites were investigated.

\section{EXPERIMENTAL PROCEDURE}

$\mathrm{PI} / \mathrm{BaTiO}_{3}$ hybrid composite films for flexible dielectric capacitors were prepared by screen printing the $\mathrm{PI} / \mathrm{BaTiO}_{3}$ pastes onto indium tin oxide (ITO)-coated glass substrates, followed by baking at $90^{\circ} \mathrm{C}$ for $24 \mathrm{~h}$ and screen printing silver paste for top electrodes to finish the process procedures.

\section{Fabrication of multi-doped $\mathrm{BaTiO}_{3}$ powders}

Two types of $\mathrm{BaTiO}_{3}$ powders were used. One was purchased from Alfa Aesar Co. (Ward Hill, MA, USA, Alfa-BT) and the other was SS (SS-BT). The multidoped SS-BT powder, containing $\mathrm{La}, \mathrm{Mg}$ and $\mathrm{Sr}$ molar ratios in the range of $1-5 \%, 1-5 \%$ and $10-30 \%$, respectively, was prepared by ball mixing $\mathrm{BaCO}_{3}$, $\mathrm{TiO}_{2}, \mathrm{Mg}(\mathrm{OH})_{2}, \mathrm{La}(\mathrm{OH})_{3}$ and $\mathrm{SrCO}_{3}$ powders for $12 \mathrm{~h}$, calcining at $1000^{\circ} \mathrm{C}$ for $3 \mathrm{~h}$ and ball milling again for $24 \mathrm{~h}$ to form the stock SS-BT powder.

The Alfa- and $\mathrm{SS}_{-} \mathrm{BaTiO}_{3}$ powders underwent mechanical refinement treatments by planetary ball milling for $3 \mathrm{~h}$ and $6 \mathrm{~h}$ to form the Alfa-BT- $3 \mathrm{~h}$, Alfa-BaT-6 h, SS-BT-3 $\mathrm{h}$ and SS-BT-6h powders. Two types of chemical surface modifications were used for the $\mathrm{BaTiO}_{3}$ powders, and their effects on the dielectric properties were also exploited. The first type modified the $\mathrm{BaTiO}_{3}$ powders with hydroxyl groups, which was performed by refluxing the powders in hydrogen-peroxide-filled, three-necked bottles at $106^{\circ} \mathrm{C}$ for $12 \mathrm{~h}$. The second type covered the $\mathrm{BaTiO}_{3}$ powders with silane, which was achieved by dispersing the hydroxyl-containing powders with the GPTMS coupling agent in xylene and stirring at room temperature for $2 \mathrm{~h}$ and at $90^{\circ} \mathrm{C}$ for $24 \mathrm{~h}$, and then separating the powder and solvent using a centrifuge.

\section{Synthesis of organosoluble PIs}

Organosoluble, transparent and flexible PIs were prepared using two different approaches. The first PI (PI-1) of 4,4'-oxydiphthalic anhydride (ODPA)/2,2bis(3-amino-4-hydroxyphenyl)hexafluoropropane (6F-OH diamine) (Scheme 1) was prepared from ODPA and 6F-OH diamine. The second coPI (PI-2) of ODPA/6F-OH diamine/4,4'-oxydianiline (ODA) (Scheme 2) was synthesized from two types of diamine monomers, $6 \mathrm{~F}-\mathrm{OH}$ and ODA, with dianhydride ODPA. For PI-2, after the diamines of $6 \mathrm{~F}-\mathrm{OH}$ and ODA were dissolved in $\mathrm{m}$-cresol, dianhydride ODPA with a few drops of isoquinoline as a catalyst was added into the $6 \mathrm{~F}-\mathrm{OH} / \mathrm{ODA}$ solution, and the reaction temperature was increased to $180^{\circ} \mathrm{C}$ for $0.5 \mathrm{~h}$, followed by an increase to $200^{\circ} \mathrm{C}$ for $15 \mathrm{~h}$. The resulting white, fiber-like coPI PI-2 was obtained by precipitation from methanol.

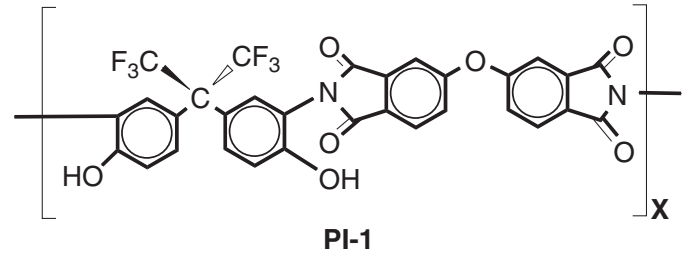

Scheme $1 \mathrm{PI}$ of ODPA/6F-OH diamine (PI-1).

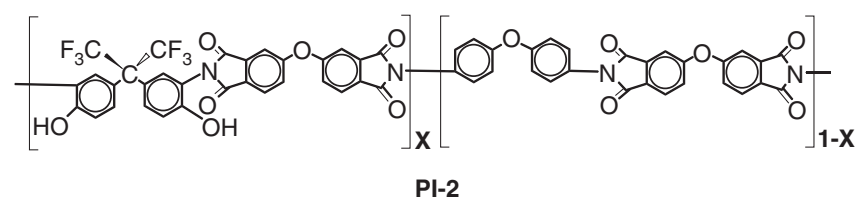

Scheme 2 PI of ODPA/6F-OH diamine/ODA (PI-2).

\section{Fabrication of $\mathrm{PI} / \mathrm{BaTiO}_{3}$ hybrid composites}

The pastes for the screen-printed films were prepared by dispersing the $\mathrm{BaTiO}_{3}$ powders into the PI-2 solution in dimethylacetamide with total ceramic volume percentages of $20,30,40$ and $50 \%$, abbreviated as BT20, BT30, BT40 and BT50, respectively. The printed films were dried at $90^{\circ} \mathrm{C}$ for $24 \mathrm{~h}$. The effects of mechanical milling of the ceramic fillers on the performance of the PI-2/BT30 and PI-2/BT50 composite films were investigated. Chemical surface modifications were executed on $\mathrm{BaTiO}_{3}$ of the PI-2/BT30 composite films.

\section{Characterization}

The surface morphology of the films was examined using a field-emission scanning electron microscope (FE-SEM, JSM 6500F; JEOL, Tokyo, Japan). Phase identification of the $\mathrm{BaTiO}_{3}$ powder was determined using X-ray diffraction (XRD, Rigaku D/Max-RC, Tokyo, Japan). A laser-scattering particle-size distribution analyzer (Horiba LA-950, Kyoto, Japan) was used to measure the milled and non-milled particle sizes of the $\mathrm{BaTiO}_{3}$ powders. The weight loss of the pure PIs was analyzed using a thermogravimetric analyzer (TA Instrument Q500, New Castle, DE, USA) at a heating rate of $20{ }^{\circ} \mathrm{C} \mathrm{min}^{-1}$ up to $800^{\circ} \mathrm{C}$ under air. The surfaces of the chemically modified $\mathrm{BaTiO}_{3}$ powders were investigated using Fourier Transform Infrared Spectrometer (FT-IR) (FTS-1000; Digilab, Holliston, MA, USA). The relative dielectric constants and loss tangents of the powders were measured at $25^{\circ} \mathrm{C}$ using a semiconductor device analyzer mainframe (B1500A; Agilent, Santa Clara, CA, USA) with a frequency of $10 \mathrm{kHz}$ and an average voltage of $\pm 1 \mathrm{~V}$.

\section{RESULTS AND DISCUSSION}

\section{PI-1 of ODPA/6F-OH diamine and PI-2 of ODPA/6F-OH diamine/ODA}

Figure 1 presents the thermogravimetric analyses of the pure PI- 1 and PI-2 polymers in air. The pure PI displayed high thermo-oxidative stability. The decomposition temperature $\left(T_{\mathrm{d}}\right)$ at $10 \%$ weight loss was approximately $515^{\circ} \mathrm{C}$ for both PIs. PI-2 had a slightly higher $T_{\mathrm{d}}$ value than PI-1. The original purpose of incorporating the ODA monomer was to reduce the costs of chemicals by reducing the amount of $6 \mathrm{~F}$ $\mathrm{OH}$ diamine and ODPA used while retaining the organosolubility of PIs. The thermogravimetric analyzer results demonstrated that the cost-effective PI-2 also retained thermal stability above $500{ }^{\circ} \mathrm{C}$.

For dielectric properties, the PI-1 and PI-2 exhibited $K$-values of $5.7 \pm 0.1$ and $7.4 \pm 0.1$ with a loss tangent of 0.02 and 0.03 , respectively. The PI-2 derived from the partial replacement of $6 \mathrm{~F}-\mathrm{OH}$ with ODA improved the polarizability of PI-1 while retaining its organosolubility. Although more polar groups were present for the $6 \mathrm{~F}-\mathrm{OH}$ in $\mathrm{PI}-1$, the dipoles partially cancelled because of the space configuration. However, ODA with the amino group in the orientation of easily enhanced polarization (Scheme 2) could contribute 
higher dielectricity. Because of its higher dielectricity, PI-2 was used for the following experiments.

\section{$\mathrm{BaTiO}_{3}$ powders and bulk samples}

The particle sizes of the Alfa-BT and stock SS-BT powders were in the range of $240-700$ and $220-350 \mathrm{~nm}$, respectively. The stock SS-BT powder had a narrower size distribution. The maximum detected intensity of the particle sizes was located at 420 and $300 \mathrm{~nm}$ for the Alfa- and SS-BT powders, respectively. Figure 2 presents the X-ray diffraction analyses of the two types of powders. Alfa-BT had a tetragonal structure and SS-BT had a cubic structure. Because of the multi-doping, the paraelectricity (cubic)-to-ferroelectricity (tetragonal) Curie point $\left(T_{\mathrm{c}}\right)$ with the highest $K$ shifted to room temperature for SS-BT. ${ }^{16}$ The $1300{ }^{\circ} \mathrm{C}$-sintered bulk samples had $K$-values of 2260 and 7290 for the Alfa- and SS-BT powders, respectively, as both bulk samples had the same loss tangent of 0.03 . Once $T_{\mathrm{c}}$ is shifted, the dielectricity is enhanced at room temperature. The cubic $\mathrm{BaTiO}_{3}$ bulk sample with its $T_{\mathrm{c}}$ near room temperature became easily polarized under an electric field and exhibited a larger $K$-value.

\section{$\mathrm{PI}-2 / \mathrm{BaTiO}_{3}$ composites with different filler volume contents}

Figure 3 demonstrates the variation of the dielectric constant for the PI-2/Alfa-BT and PI-2/SS-BT hybrid composites depending on the filler volume percentage. The printed layers had a film thickness of 9-11 $\mu \mathrm{m}$. The $K$-values increased with $\mathrm{BaTiO}_{3}$ content. The PI-2/AlfaBT50 and PI-2/SS-BT50 films were characterized by the highest $K$-values of $31 \pm 1$ and $52 \pm 2$, respectively, for each system. The

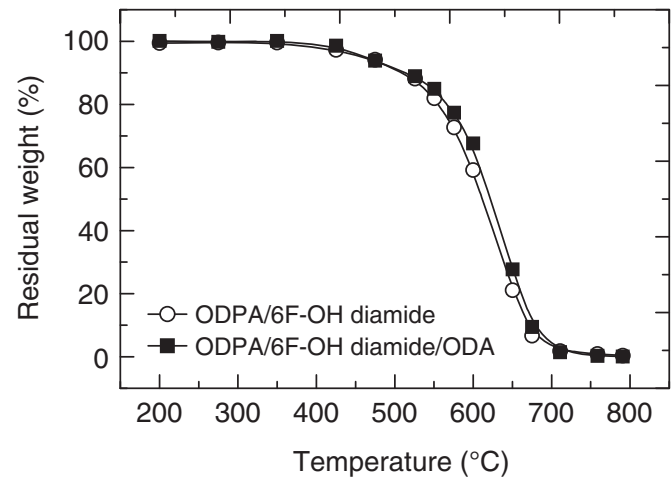

Figure 1 thermogravimetric analyzer thermograms of $\mathrm{PI}-1$ of ODPA/6F-OH diamine and $\mathrm{PI}-2$ of ODPA/6F-OH diamine/ODA in air.

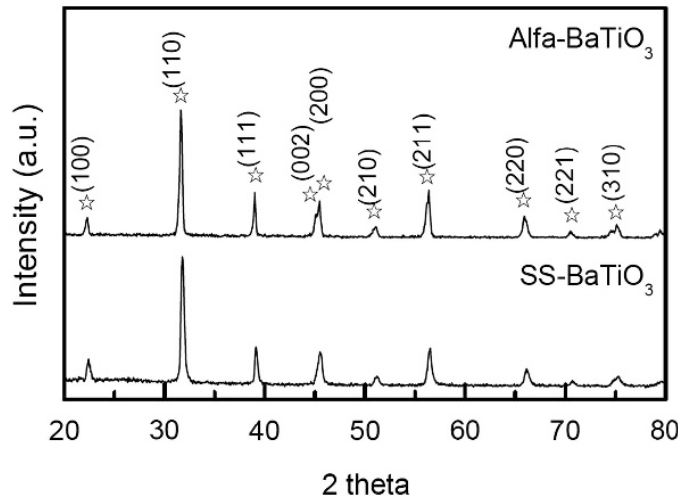

Figure 2 X-ray diffraction (XRD) analyses of the commercially available (Alfa) and SS-BT starting powders. dielectric properties of the PI-2/Alfa-BT system were similar to the published data for PI hybrid films prepared using the two-step process. ${ }^{20,21}$ However, our PI-2/SS-BT system exhibited greatly improved dielectricity. Thus, the multi-doped $\mathrm{BaTiO}_{3}$ powder with a cubic structure and higher $K$ in the bulk samples can contribute to a large increase in the dielectricity of the hybrid composites.

Figure 4 presents FE-SEM images of the (a) PI-2/Alfa-BT and (b) PI-2/SS-BT hybrid composites with filler volume percentages of (i) $20 \%$, (ii) $30 \%$, (iii) $40 \%$ and (iv) $50 \%$. The FE-SEM images of the PI-2/BT20 films (Figures 4ai and bi) illustrate the apparent difference in the dispersion behavior of $\mathrm{BaTiO}_{3}$ in PI for our two systems. The Alfa-BT powder has a greater tendency to aggregate than the SS-BT, and this aggregation behavior remains for higher $\mathrm{BaTiO}_{3}$ contents. For PI-2/BT50, polymer-filled gaps are present between the Alfa-BT aggregates; however, the SS-BT powders appear to be closely packed and to form a smooth surface. With similar particle sizes for the Alfa-BT and SS-BT powders, the strong difference in dispersion could be attributed to the different surface-charge states of the fillers caused by the doping effect. The surface charge must balance the charge in the space-charge zone in the powder. For the undoped Alfa-BT powders, the space-charge zone is expected to be negatively charged ${ }^{23}$ and is balanced by the positively charged surface charges. These positive charges on the surface can attract polar water molecules, which leads to filler aggregation before incorporation into the PI matrix. For multi-doped SS-BT powders, the surface-charge state reverses. No filler aggregation was expected for the SS-BT stock powder because of its difficulty with humidity absorption. The different degrees of aggregation were clearly distinguished for the starting powders. The inversion in the surface-charge state due to the doping effect had been previously demonstrated for $\mathrm{TiO}_{2}{ }^{23,24}$ Without the interruption of humidity, the Van der Waals force between the SS-BT powders due to the electric dipoles can link the filler particles to form a continuous network. Therefore, the aggregation or the linkage formation of fillers in hybrid films depends upon their surface-charge state.

$\mathrm{PI}-2 /\left(30\right.$ and 50 vol\% $\left.\mathrm{BaTiO}_{3}\right)$ with mechanically treated fillers Figure 5 a presents the X-ray diffraction analyses of the SS-BT powders after planetary ball milling. The SS-BT powders became finer, as demonstrated by the shift of the diffraction peaks to lower angles. The crystallinity of these powders was also degraded, which was determined from the reduced diffraction intensity. The measured particle sizes were 260 and $128 \mathrm{~nm}$ for the SS-BT powders after planetary ball

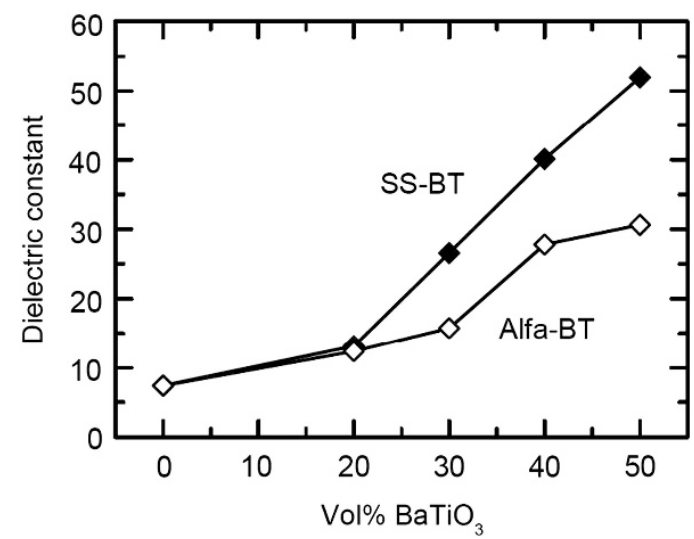

Figure 3 Variations of the dielectric constants of $\mathrm{PI}-2 / \mathrm{Alfa}-\mathrm{BaTiO}_{3}$ and $\mathrm{PI}-2$ / $\mathrm{SS}-\mathrm{BaTiO}_{3}$ hybrid composites with filler volume percentage. 


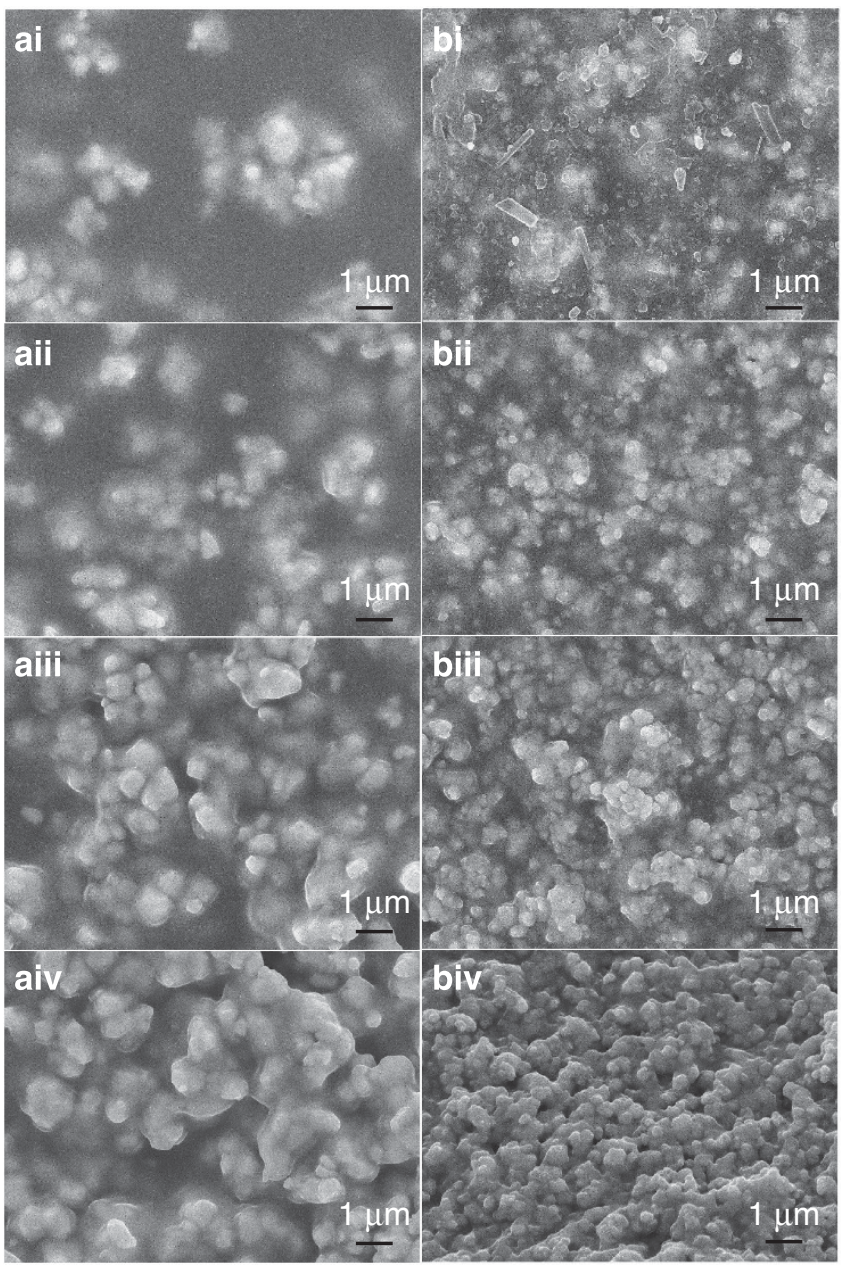

Figure $4 \mathrm{FE}-\mathrm{SEM}$ images of (a) $\mathrm{PI}-2 / \mathrm{Alfa}^{-} \mathrm{BaTiO}_{3}$ and (b) $\mathrm{PI}-2 / \mathrm{SS}-\mathrm{BaTiO}_{3}$ hybrid composites with filler volume percentages of (i) $20 \%$, (ii) $30 \%$, (iii) $40 \%$ and (iv) $50 \%$.

milling for 3 and $6 \mathrm{~h}$, respectively, compared with $300 \mathrm{~nm}$ for the stock SS-BT powder. Figure $5 \mathrm{~b}$ illustrates the variation in the dielectric constants of the PI/SS-BT hybrid composites depending on the filler content, where the BT powders were mechanically treated for $3 \mathrm{~h}$ and $6 \mathrm{~h}$. After milling for $3 \mathrm{~h}$ and $6 \mathrm{~h}$ in ethanol, the dielectric constants significantly decreased to $16-18$ for PI-2/SS-BT30 and 28 for PI-2/SS-BT50. The 3-h milling of SS-BT was sufficient for its hybrid films, and no further changes in dielectricity were observed after a milling duration of $6 \mathrm{~h}$. The dielectric constants of PI-2/SSBT30-3 h and PI-2/SS-BT30-6h with the planetary ball-milled fillers were almost identical and also the same as that of PI-2/Alfa-BT30 at 16 , which indicates that (1) the particle-size effect on dielectricity of hybrid films is not significant and (2) multiple doping in our mechanically milled $\mathrm{BaTiO}_{3}$ to modify its properties for organic/ inorganic composites is redundant.

Figure 6 presents FE-SEM images of the (a) PI-2/SS-BT30 and (b) PI-2/SS-BT50 hybrid composites with their fillers (i) untreated or planetary ball milled for (ii) $3 \mathrm{~h}$ or (iii) $6 \mathrm{~h}$. For the PI-2/SS-BT30 hybrid composite in Figures 6ai-iii, the particle size of SS-BT-3h $(260 \mathrm{~nm})$ did not change significantly from that of SS-BT $(300 \mathrm{~nm})$; however, the particle connection was broken and the particles were dispersed in the matrix. For PI-2/SS-BT50 in Figures 6bi-iii, although
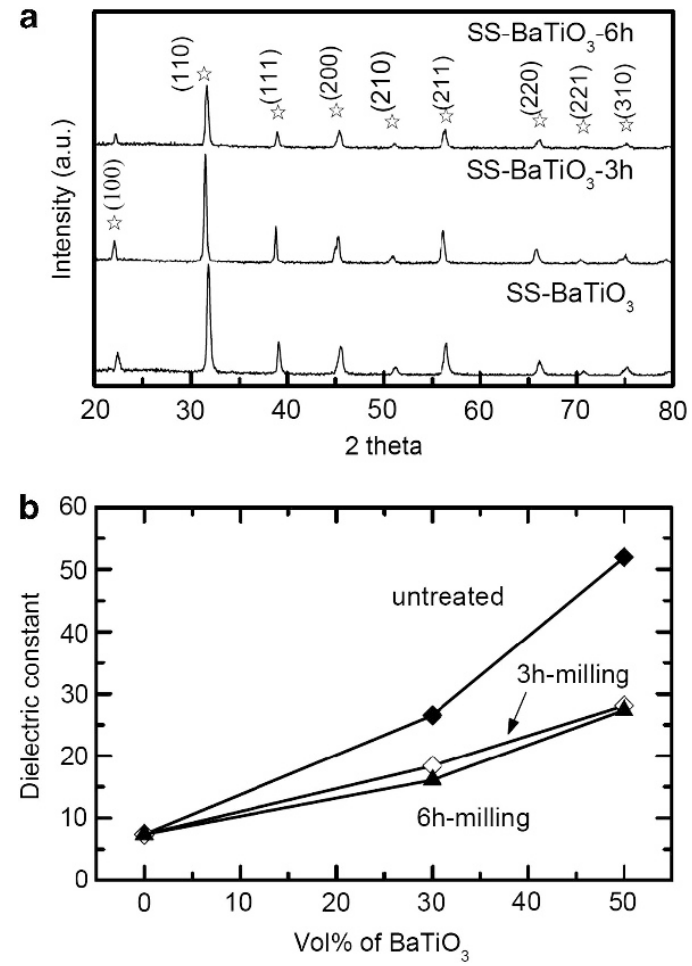

Figure 5 (a) XRD analyses of $\mathrm{SS}-\mathrm{BaTiO}_{3}$ powders after planetary ball milling and (b) the variations of the dielectric constants of the PI-2/SS-BT hybrid composites with the filler contents of BT powders mechanically treated for 3 and $6 \mathrm{~h}$.

the dispersion of the particles is difficult to differentiate, the SS-BT$6 \mathrm{~h}$ particles in the PI-2 matrix are uniformly distributed and packed into a smooth surface with the aid of its finer particle size of $128 \mathrm{~nm}$ (Figure 6biii). However, the untreated SS-BT particles in the composite films was not closely packed, which led to a rough surface (Figure 6bi). Because of the difficulty in differentiating the filler state in the PI-2/SS-BT50 system from the observations of SEM images, the large changes in $K$ (Figure $5 b$ ) cannot be related to the information obtained from Figure $6 \mathrm{~b}$.

\section{$\mathrm{PI}-2 /\left(30\right.$ vol\% $\left.\mathrm{BaTiO}_{3}\right)$ with chemically surface-treated fillers}

Figure 7 presents FE-SEM images of (a) PI/(30 vol\% Alfa-BT) and (b) $\mathrm{PI} /(30$ vol\% SS-BT) hybrid composites with their fillers (i) untreated, (ii) $\mathrm{H}_{2} \mathrm{O}_{2}$-treated and (iii) GPTMS-treated. The chemical surface modifications using $\mathrm{H}_{2} \mathrm{O}_{2}$ did not result in any significant changes in particle dispersion for either of the systems. However, the GPTMS coupling agent apparently improved the particle dispersion for the two systems, in particular for PI/SS-BT (Figure 7biii). Finer particles dispersed in PI were easily observed. Iijima et al. ${ }^{14}$ demonstrated the interfacial reaction between GPTMS and $\mathrm{BaTiO}_{3}$ with hydroxyl surface groups. The table in Figure 7 illustrates the dielectric variations of hybrid composites with chemical modifications. The chemical surface modifications decreased the dielectric constants from 16 to 14 for PI-2/Alfa-BT30 but from 27 to 13-14 for PI-2/SS-BT30. Although the $\mathrm{H}_{2} \mathrm{O}_{2}$ surface treatment did not reveal a clear effect in dispersion for the SS-BT powders (Figure 7bi compared with Figure 7bii), its effect on the dielectric properties was as effective as the GPTMS treatment. This result implies that the dielectricity of hybrid composites is determined from a microscopic viewpoint. 


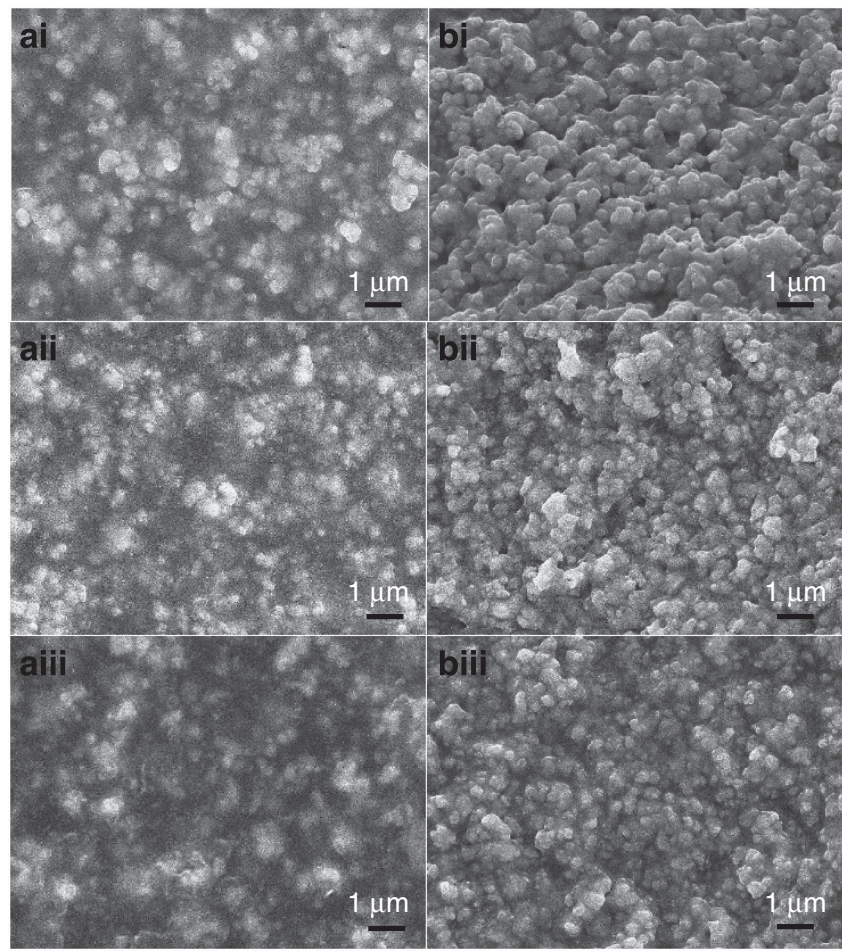

Figure 6 FE-SEM images of (a) $\mathrm{PI}-2 /(30$ vol\% SS-BaTiO 3 ) and (b) $\mathrm{PI}-2 /$ (50 vol\% $\mathrm{SS}-\mathrm{BaTiO}_{3}$ ) hybrid composites with their fillers (i) untreated or planetary ball milled for (ii) $3 \mathrm{~h}$ and (iii) $6 \mathrm{~h}$.

Figure 8a displays the FT-IR measurements for (i) SS-BT powders and for these powders after chemical surface modifications by (ii) $\mathrm{H}_{2} \mathrm{O}_{2}$ and (iii) a silane coupling agent. Figure $8 \mathrm{~b}$ presents the FT-IR measurements for SS-BT powders mechanically milled for 3 and $6 \mathrm{~h}$. After modification by $\mathrm{H}_{2} \mathrm{O}_{2}$, a very broad peak at $3500 \mathrm{~cm}^{-1}$ indicates the presence of the $\mathrm{OH}^{-}$group. ${ }^{14,21}$ After $\mathrm{BaTiO}_{3}$ was treated by GPTMS, two peaks at $\sim 1200 \mathrm{~cm}^{-1}$ related to the Si-O-Si asymmetric stretching and vibration and two small peaks at $\sim 2900 \mathrm{~cm}^{-1}$ related to the asymmetric and symmetric vibrations of $-\mathrm{CH}_{2}-$ indicated a successful reaction or chemisorption of GPTMS on SS-BT (Figure 8aiii). ${ }^{14,21}$ For the mechanical milling experiments, the $\mathrm{OH}^{-}$functional group was weak after the powders were milled for $3 \mathrm{~h}$ but became apparent after a longer milling duration of $6 \mathrm{~h}$.

\section{Dielectricity and particle aggregation/separation}

Our PI-2/SS-BT composite films display high dielectric constants when the fillers do not undergo mechanical or chemical treatments. The highest $K$-values of the hybrid composites were 27 and 52 for SSBT contents of 30 and $50 \mathrm{vol} \%$, respectively. These values are comparable to those for epoxy- or polyvinylidene fluoride-based hybrid composites ${ }^{14-19}$ and are even comparable to the highest $K$ value reported by Chon et al. ${ }^{13}$ Compared with the PI-matrix system, our results yielded higher dielectric constants. Our improved result involves the utilization of $6 \mathrm{~F}-\mathrm{OH}$ diamine (Scheme 1) and ODA (Scheme 2). The $6 \mathrm{~F}-\mathrm{OH}$ diamine has a very similar structure to halogenated bisphenol $\mathrm{A}$, as used in the work of Chon et al. ${ }^{13}$ Therefore, $6 \mathrm{~F}-\mathrm{OH}$ diamine can possess high polarizability and enhance the dielectric property of our PI. Without the $\mathrm{CF}_{3}$ functional group, PI derived from different precursors has a $K$-value of $3-4 .^{20,21}$ The ODA-containing PI-2 $(K=7.4)$, with an aniline-
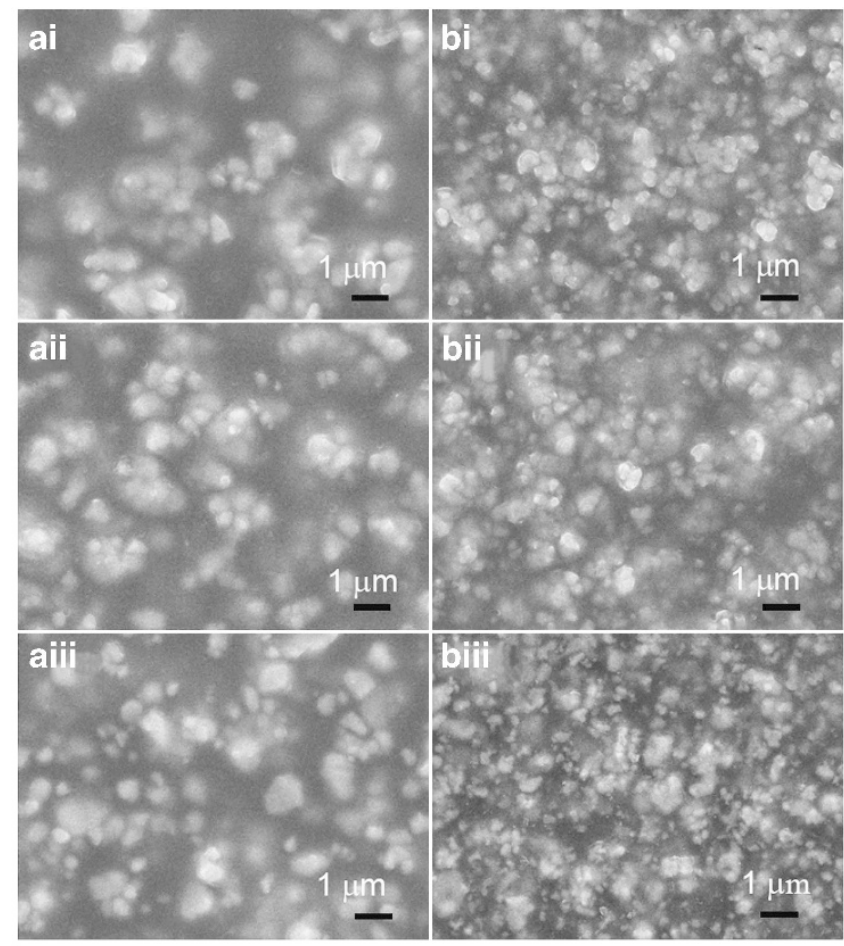

\begin{tabular}{|c|c|c|c|}
\hline & $\begin{array}{c}\text { Raw } \\
\text { powder }\end{array}$ & $\begin{array}{c}\mathrm{H}_{2} \mathrm{O}_{2} \text {-treated } \\
\text { Powder }\end{array}$ & $\begin{array}{c}\text { GPTMS-treated } \\
\text { powder }\end{array}$ \\
\hline Alfa-BT & & & \\
\hline $\mathrm{K}$ & $15.8 \pm 0.4$ & $14.2 \pm 2.1$ & $14.2 \pm 1.8$ \\
\hline $\tan \delta$ & $0.02 \pm 0.01$ & 0.02 & 0.02 \\
\hline SS-BT & & & \\
\hline $\mathrm{K}$ & $26.6 \pm 1.0$ & $13.3 \pm 1.7$ & $14.3 \pm 1.6$ \\
\hline $\tan \delta$ & $0.03 \pm 0.03$ & $0.02 \pm 0.01$ & $0.03 \pm 0.01$ \\
\hline
\end{tabular}

Figure $7 \mathrm{FE}-\mathrm{SEM}$ images of (a) $\mathrm{PI}-2 /(30$ vol\% Alfa-BaTiO 3 ) and (b) $\mathrm{PI}-2 /$ (30 vol\% SS-BaTiO ${ }_{3}$ ) hybrid composites with their fillers (i) untreated, (ii) $\mathrm{H}_{2} \mathrm{O}_{2}$-treated and (iii) GPTMS-treated. The attached table shows the dielectric variations of hybrid composites with the chemical modifications.

oxygen-aniline bond angle $<180^{\circ}$ to enhance polarizability, shows a $30 \%$ increase in the $K$-value compared with our PI-1 $(K=5.7)$. Therefore, our PI-2 has nearly a one-fold increase in $K$ compared with the fluorine-free PI $(K=3-4)$. The other reason for the improved dielectricity of the hybrid film is related to the $\mathrm{BaTiO}_{3}$ powder. The strong dielectric behavior of PI-2/SS-BT can be attributed to the formation of a continuous filler network to induce the stronger dipole-dipole interaction along with the particle network, which can form continuous and aligned dipoles and induce extra electrical charges on the electrodes to increase the charge density and lead to a higher dielectric constant. However, the PI/Alfa-BT composites have the problem of filler aggregation (Figure 4aiv), which fails to build up the interaction network and results in inferior dielectricity.

From the results for the mechanical treatment and the $\mathrm{H}_{2} \mathrm{O}_{2}$ treatment of PI-2/SS-BT30, the dielectric constant is greatly decreased, whereas the particle size (260 for SS-BT-3h vs $300 \mathrm{~nm}$ for SS-BT) does not show an obvious change. Therefore, a size effect on dielectricity for SS-BT can be excluded. Upon chemical modification of the multi-doped SS-BT powders by $\mathrm{H}_{2} \mathrm{O}_{2}$, the dielectric constants of PI-2/SS-BT greatly decreased. The decrease in $K$ resulted in the 

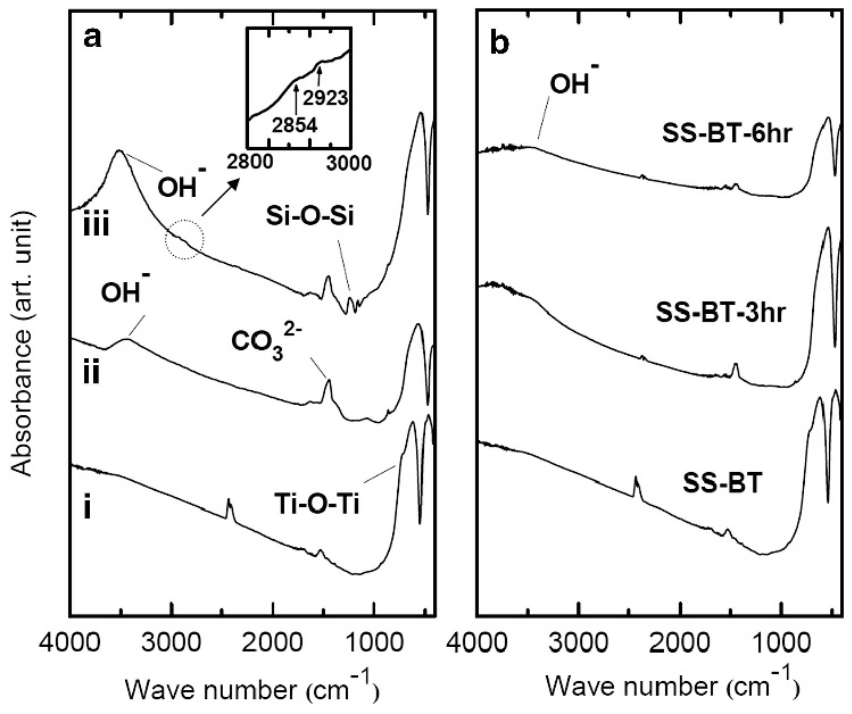

Figure 8 (a) FT-IR measurements for (i) SS-BT powders and for these powders after chemical surface modifications using (ii) $\mathrm{H}_{2} \mathrm{O}_{2}$ and (iii) a silane coupling agent. (b) FT-IR measurements for SS-BT powders after mechanically milling for 3 and $6 \mathrm{~h}$. The inset in (a-iii) was the enlarged spectrum located in the dotted cycle.

dielectric properties of PI-2/SS-BT being comparable to those of the PI-2/Alfa-BT films. This modification can provide $\mathrm{OH}^{-}$surface groups on an atomic scale to prevent direct contacts of SS-BT powders from the formation of a continuous connection by charge repulsion to allow infiltration of the polymer matrix between fillers and to block the dipole interaction path. This microscopic modification cannot be revealed from the macroscopic SEM images of the composite films containing untreated SS-BT (Figure 7bi) and $\mathrm{H}_{2} \mathrm{O}_{2}-$ treated SS-BT (Figure 7bii). This $\mathrm{OH}$ generation on the filler surface has a significant effect on the dielectric property, decreasing the $K$ values of the composites from 26.6 to 13.3. However, GPTMS as a long-chain coupling agent chemically absorbed on SS-BT can provide effective stereo hindrance to block the formation of a filler interaction network, which can lead to poor dielectricity. Scheme 3 displays $\mathrm{BaTiO}_{3}$ particles in PI in three different states: aggregation, continuous network and particle separation after mechanical or chemical modifications.

Based upon the results of the chemical modification, the effect of a mechanical milling treatment on the dielectricity of hybrid composites can be easily understood. Although the dielectricity decreases in hybrid composites with fillers of a smaller particle size,${ }^{15-17}$ the decrease in $K$ for our PI-2/SS-BT composites with the mechanically milled fillers is attributed to the particle separation after considering a limited change in the filler particle size after milling, the same $K$ values of composites with the fillers milled for 3 and $6 \mathrm{~h}$ and the strong effect induced by the $\mathrm{OH}^{-}$group of the $\mathrm{H}_{2} \mathrm{O}_{2}$-treated fillers. Our planetary ball milling provides the high-impact energy to grind the ceramic fillers. Under the environment of ethanol as a solvent, the hydroxyl groups on the fillers increase with an increase in the milling duration (Figure $8 \mathrm{~b}$ ). Because the functional group is on an atomic scale, a spectroscopic analysis is only detectable after a longer milling duration of $6 \mathrm{~h}$. Apparently, the small amount of $\mathrm{OH}^{-}$groups on the fillers milled for $3 \mathrm{~h}$ is sufficient to greatly reduce the dielectricity (Figure 5b), which is consistent with our $\mathrm{H}_{2} \mathrm{O}_{2}$-treated result.

The effects of mechanical milling and chemical surface modification of filler particles on other physical properties can also be

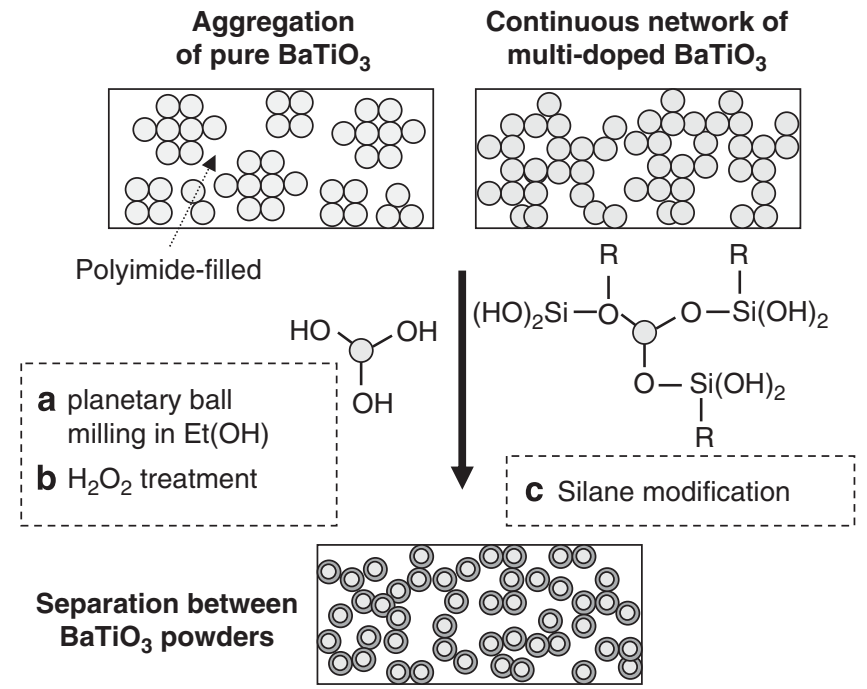

Particle states in polyimide/ $\mathrm{BaTiO}_{3}$ hybrid films

Scheme $3 \mathrm{BaTiO}_{3}$ particles in $\mathrm{PI}$ at three different states: aggregation, continuous network and particle separation after a mechanical or chemical treatment.

predicted. The thermal conductivity of the hybrid composites is one example. The thermal conduction of insulating-type fillers requires a rigid and connective filler network for phonon propagation. Once the fillers are separated by polymers of low thermal conduction, the phonons are scattered at the polymer/filler interface. Therefore, thermal conduction is difficult, and the thermal conduction of hybrid composites is much lower than that of thermally conductive fillers. ${ }^{25,26}$ With an increase in the volume ratio of fillers and better coherence at the interfaces, higher thermal conduction can be achieved because of the formation of a conduction path. ${ }^{27}$

\section{CONCLUSIONS}

$\mathrm{PI} / \mathrm{BaTiO}_{3}$ hybrid composites with different filler contents and mechanical and chemical modifications of the $\mathrm{BaTiO}_{3}$ fillers have been investigated and discussed. These composites use the organosoluble PI as a matrix and can therefore be fabricated at $90{ }^{\circ} \mathrm{C}$ instead of $300{ }^{\circ} \mathrm{C}$ using the PAA route. This low-temperature process can use $\mathrm{PI} / \mathrm{BaTiO}_{3}$ as a capacitor to integrate with flexible electronics. Our composite films with self-synthesized and multi-doped $\mathrm{BaTiO}_{3}$ fillers have dielectric constants of 27 and 52 at filler contents of 30 and 50 vol\%, respectively. The much higher dielectricity is related to the utilization of $6 \mathrm{~F}-\mathrm{OH}$ diamine and ODA with high polarizability for PI, formation of a continuous filler network for easy dipole-dipole interaction and propagation of induced charges to the electrodes. The lower dielectricity for composites with the purchased $\mathrm{BaTiO}_{3}$ is attributed to the filler aggregation but results from the particle separation for the composites with our SS fillers undergoing mechanical and chemical surface modifications. The $\mathrm{OH}^{-}$modification on the fillers on an atomic scale can easily deteriorate the composite dielectricity by allowing penetration of the polymer matrix between fillers, thereby blocking the continuous interaction path.

\section{CONFLICT OF INTEREST}

The authors declare no conflict of interest. 


\section{ACKNOWLEDGEMENTS}

We acknowledge the financial support of the National Science Council under grant number 100-2221-E-011-145 and the National Taiwan University of Science and Technology under grant numbers 100H451201 and 100H451202.

1 Forrest, S. R. The path to ubiquitous and low-cost organic electronic appliances on plastic. Nature (London) 428, 911-918 (2004).

2 Sun, Y. \& Rogers, J. A. Inorganic semiconductors for flexible electronics. Adv. Mater. 19, 1897-1919 (2007).

3 Ahmad, Z. \& Mark, J. E. Polyimide-ceramic hybrid composites by the sol-gel route. Chem. Mater. 13, 3320-3330 (2001).

4 Huang, J. C., Zhu, Z. K., Ma, X. D., Qian, X. F. \& Yin, J. Preparation and properties of montmorillonite/organo-soluble polyimide hybrid materials prepared by a one-step approach. J. Mater. Sci. 36, 871-877 (2001).

5 Morikawa, A., Tyoku, Y., Kakimoto, M. A. \& Imai, Y. Conformational energy calculations on the crystalline state of mesogenic polyesters. Polym. J. 24, 107-113 (1992).

6 Bartolotta, A. \& Calandra, P. Macromol indication of local phase separation in polyimide/silica hybrid polymers. Chem. Phys. 211, 1784-1792 (2010).

7 Zhang, C., Zhang, M., Cao, H., Zhang, Z., Wang, Z., Gao, L. \& Ding, M. Synthesis and properties of a novel isomeric polyimide/ $\mathrm{SiO}_{2}$ hybrid material. Compos. Sci. Technol. 67, 380-389 (2007).

8 Cornelius, C. J. \& Marand, E. Hybrid inorganic-organic materials based on a 6FDA6FpDA-DABA polyimide and silica: physical characterization studies. Polymer 43, 2385-2400 (2002).

9 Wang, Y. W. \& Chen, W. C. Synthesis, properties, and anti-reflective applications of new colorless polyimide-inorganic hybrid optical materials. Compos. Sci. Technol 70, 769-775 (2010).

10 Suac, H. W. \& Chen, W. C. High refractive index polyimide-nanocrystalline- titania hybrid optical materials. J. Mater. Chem. 18, 1139-1145 (2008).

$11 \mathrm{Ma}$, P., Nie, W., Yang, Z., Zhang, P., Li, G., Lei, Q., Gao, L., Ji, X. \& Ding, M. Preparation and characterization of polyimide $/ \mathrm{Al}_{2} \mathrm{O}_{3}$ hybrid films by sol-gel process. J. Appl. Polym. Sci. 108, 705-712 (2008).

12 Kinoshita, K. \& Yamaji, A. Grain-Size effects on dielectric properties in barium titanate ceramics. J. Appl. Phys. 47, 371-373 (1976).
13 Chon, J., Ye, S., Cha, K. J., Lee, S. C., Koo, Y. S., Jung, J. H. \& Kwon, Y. K. High-K dielectric sol-gel hybrid materials containing barium titanate nanoparticles. Chem. Mater. 22, 5445-5452 (2010).

14 lijima, M., Sato, N., Lenggoro, I. W. \& Kamiya, H. Surface modification of batio 3 particles by silane coupling agents in different solvents and their Effect on dielectric properties of $\mathrm{BaTiO}_{3}$ /epoxy composites. Colloids and Surf. A 352, 88-93 (2009).

15 Dang, Z. M., Yu, Y. F., Xu, H. P. \& Bai, J. Study on microstructure and dielectric property of the $\mathrm{BaTiO}_{3}$ /epoxy resin composites. Compos. Sci. Technol. 68, 171-177 (2008).

16 Kuo, D. H., Chang, C. C., Su, T. Y., Wang, W. K. \& Lin, B. Y. Dielectric properties of three ceramic/epoxy composites. Mater. Chem. Phys. 85, 201-206 (2004).

17 Kuo, D.H., Wang, C. H. \& Tsai, W. P. Donor- and acceptor-cosubstituted $\mathrm{BaTiO}_{3}$ for nonreducible multilayer ceramic capacitors. Ceram. Int. 32, 1-5 (2006).

$18 \mathrm{Li}$, J., Claude, J., Norena-Franco, L. E., Seok, S. I. \& Wang, Q. Electrical energy storage in ferroelectric polymer nanocomposites containing surface- functionalized $\mathrm{BaTiO}_{3}$ nanoparticles. Chem. Mater. 20, 6304-6306 (2008).

19 Kim, P., Jones, S. C., Hotchkiss, P. J., Haddock, J. N., Kippelen, B., Marder, S. R. \& Perry, J. W. Phosphonic acid-modified barium titanate polymer nanocomposites with high permittivity and dielectric strength. Adv. Mater. 19, 1001-1005 (2007).

20 Dang, Z. M., Lin, Y. Q., Xu, H. P., Shi, C. Y., Li, S. T. \& Bai, J. Fabrication and dielectric characterization of advanced $\mathrm{BaTO}_{3} /$ polyimide nanocomposite films with high thermal stability. Adv. Funct. Mater. 18, 1509-1517 (2008).

21 Xie, S. H., Zhu, B. K., Wei, X. Z., Xu, Z. K. \& Xu, Y. Y. Polyimide/BaTiO 3 composites with controllable dielectric properties. Composites: Part A 36, 1152-1157 (2005).

$22 \mathrm{Lee}, \mathrm{J}$., Ko, Y. \& Kim, J. Effect of poly(amic acid)-treated $\mathrm{BaTiO}_{3}$ on the dielectric and mechanical properties of $\mathrm{BaTiO}_{3} /$ polyimide composites. Macromol. Res. 18, 200-203 (2010).

23 Ikeda, J. A. S. \& Chiang, Y. M. Space charge segregation at grain boundaries in titanium dioxide: II, model experiments. J. Am. Ceram. Soc. 76, 2437-2446 (1993).

24 Chiang, Y. M., Birnie, III D. \& Kingery, W. D. Physical Ceramics: Principles for Ceramic Science and Engineering (Wiley, New York, 1997).

25 Zhou, W., Qi, S., Li, H. \& Shao, S. Study on insulating thermal conductive BN/HDPE composites. Thermochim. Acta. 452, 36-42 (2007).

26 Zhou, W. Thermal and dielectric properties of the AIN particles reinforced linear lowdensity polyethylene composites. Thermochim. Acta. 512, 183-188 (2011).

27 Sato, K., Horibe, H., Shirai, T., Hotta, Y., Nakano, H., Nagai, H., Mitsuishid, K. \& Watari, K. Thermally conductive composite films of hexagonal boron nitride and polyimide with affinity-enhanced interfaces. J. Mater. Chem. 20, 2749-2752 (2010). 